\title{
EVOLUÇÃO GERENCIAL DE UMA EMPRESA PROJETISTA BRASILEIRA : DA IMPLEMENTAÇÃO DE MODELOS DE GESTÃO AO DESENVOLVIMENTO DO SISTEMA DE INFORMAÇÕES GERENCIAIS
}

\author{
Management Evolution of a Brazilian Design Firm : From \\ the Management Model Implementation to Information \\ System Development
}

\author{
Flávia Souza', Nathália de Paula', Silvio Burrattino Melhado²
}

RESUMO Este artigo foi desenvolvido no contexto do PDGEP (Programa de Desenvolvimento Gerencial para Empresas de Projeto) e tem como objetivo discutir a evolução gerencial de uma empresa projetista, por meio da análise do processo de desenvolvimento de ferramentas de gestão. Para tanto, dados foram coletados em duas etapas de pesquisa. Na Etapa I, retratase a participação da empresa durante a implementação do modelo de gestão ao longo das edições do PDGEP e o desenvolvimento de ferramentas de gestão. Nesta etapa, o método de pesquisa utilizado foi a pesquisa-ação. Na Etapa II, o trabalho de pesquisa foi conduzido por meio de entrevistas estruturadas, com objetivo de diagnosticar o estado gerencial da empresa e, a partir do levantamento das deficiências e dificuldades apresentadas no desenvolvimento do Sistema de Informações Gerenciais (SIG), analisar as potencialidades para a evolução das práticas de gestão da empresa. Quanto às deficiências encontradas, estão relacionadas principalmente à: análise crítica sobre a eficácia dos instrumentos de gestão do processo de projeto; necessidade da formalização do planejamento estratégico; revisão do processo de gestão de pessoas; revisão do módulo de serviços agregados; e realização de análises críticas sistemáticas do SIG. No que diz respeito às dificuldades, destaca-se o baixo envolvimento dos colaboradores da empresa nos processos de análises e tomada de decisões gerenciais.

PALAVRAS-CHAVE Gestão, empresa de projeto, informação gerencial.

\begin{abstract}
Concerning the Management Development Program for Design Firm, our aim is to discuss the management evolution of a design firm through the analysis of the development process of management tools. The data were collected in two research phases. In the first phase, it was reported the firm participation in the PDGEP editions during the management model implementation and the management tools development. In this phase, the research method used was the action research. In the second phase, the research was conducted through structured interviews in order to diagnose the design firm management current status, as well as to analyze the potential for the management practices evolution of the firm, based on the survey of the deficiencies and difficulties during the development of the Management Information System (MIS). Regarding the deficiencies, they are mainly related to critical analysis of the management tools effectiveness related to the design process; need of strategic planning formalization; review of people management process; revision of aggregated service module; conducting systematic critical analyzes of the MIS. In terms of difficulties, they are mainly related to the people involvement in the management analysis and decision-making processes.
\end{abstract}

KEYWORDS Management, design firm, management information. 


\section{INTRODUÇÃo}

Apesar do trabalho desenvolvido pelas empresas projetistas ser de extrema importância para o setor da construção civil, verifica-se que, em geral, as suas práticas de gestão limitam o seu desempenho técnico. Diante deste quadro, foi criado o Programa de Desenvolvimento Gerencial para Empresas de Projeto (PDGEP) - também conhecido como Soluções para Empresas de Projeto, iniciativa da Linha de Pesquisa em Gestão de Projetos, do Departamento de Engenharia de Construção Civil da Escola Politécnica da USP.

A Linha de Pesquisa iniciou os estudos no tema em 1996 e o programa "Soluções" foi criado em 2006, com o objetivo de promover o desenvolvimento gerencial das empresas de projeto. Esse desenvolvimento é proposto às empresas por meio da implementação de modelos de gestão, visando contribuir para a melhoria da qualidade dos produtos finais (projetos), além de facilitar o alcance das metas das empresas e a satisfação de seus clientes e contratantes.

Trata-se de um programa cooperativo entre a universidade e as empresas de projeto, com benefícios para ambas as partes. Para a universidade, o programa possibilita o desenvolvimento de pesquisas alinhadas com as problemáticas setoriais; já para as empresas, além do acompanhamento sistematizado na aplicação dos modelos de gestão, possibilita a discussão de problemas gerenciais comuns a todas as projetistas.

Até o momento, foram realizadas quatro edições do programa (anos 2006, 2007, 2008 e 2010) e a quinta, iniciada em 2011, foi finalizada em novembro de 2012. Ao longo desses anos, diversos trabalhos acadêmicos foram gerados em virtude da atuação dos pesquisadores que atuaram no programa - os títulos dos trabalhos podem ser verificados em Souza et al. (2011).

O presente artigo é mais um dos trabalhos de pesquisa, fruto da realização do PDGEP, cujo objetivo é discutir a evolução gerencial de uma empresa projetista, por meio do desenvolvimento de ferramentas de gestão, analisar o seu estado gerencial atual e as potencialidades para a evolução de suas práticas de gestão. A empresa tratada neste artigo participou das edições do programa em 2008, 2009 e 2010.

\section{METODOLOGIA DE PESQUISA}

Figura 1. Metodologia de pesquisa.

A discussão referente à evolução gerencial da empresa projetista e a análise do seu estado gerencial foi realizada por meio da coleta de dados levantados nas Etapas de Pesquisa I e II, conforme mostra a Figura 1. A partir das duas etapas, foram analisadas as potencialidades para a evolução das práticas de gestão da empresa.

Os itens 2.1 e 2.2 detalham as Etapas de Pesquisa I e II.

\section{ETAPA I: PROGRAMA DE DESENVOLVIMENTO GERENCIAL PARA EMPRESAS DE PROJETO}

O objetivo da Etapa de Pesquisa

I é retratar a participação da empresa ao longo das edições do PDGEP (2008, 2009 e 2010) durante 
a implementação do modelo de gestão proposto por Oliveira (2005) e o desenvolvimento de ferramentas de gestão (ver Figura 1).

O método de pesquisa utilizado durante os PDGEP's foi a pesquisa-ação, definido por Thiollent (2005) como um tipo de pesquisa social com base empírica, que é concebida e realizada em estreita associação com uma ação ou com a resolução de um problema coletivo, no qual os pesquisadores e os participantes representativos da situação ou do problema estão envolvidos de modo cooperativo ou participativo.

O método foi escolhido em função das peculiaridades do programa no qual a pesquisa estava inserida, que proporcionava uma ampla interação entre os pesquisadores e as empresas envolvidas. Outro aspecto relevante na escolha do método, relaciona-se ao fato de que o objeto de investigação não é constituído somente pelas empresas, mas pelo contexto em que estão inseridas e pelos problemas de diferentes naturezas encontrados nesta situação.

A rotina ${ }^{1}$ do PDGEP é composta por reuniões mensais, às quais comparecem todas as empresas participantes. Durante as reuniões são realizadas apresentações referentes aos módulos de gestão propostos por Oliveira (2005) - estrutura organizacional, planejamento estratégico, planejamento e controle do processo de projeto, gestão financeira, gestão comercial e marketing, sistema de informação, gestão de pessoas e serviços agregados ao projeto e avaliação de desempenho - promovendo a troca de experiências entre as empresas.

Durante as reuniões, também são realizadas dinâmicas, solicitações de diagnósticos e tarefas de cada módulo de gestão, desenvolvidos no dia a dia de cada empresa, resultando em alterações e desenvolvimento de sua estrutura de gestão.

O fechamento de cada edição do PDGEP² ocorre por meio de eventos, cujos objetivos incluem apresentar os resultados do desenvolvimento gerencial das empresas participantes e possibilitar a discussão de assuntos de interesse comum para as empresas de projeto do setor da construção civil.

A sistemática de trabalho utilizada nas edições do programa, das quais a empresa participou, seguiu a descrição colocada acima. No entanto, durante a edição do PDGEP iniciado em 2010, as empresas contaram com o auxílio de um colaborador - aqui denominado "colaborador de gestão" - dedicado aos estudos e à implementação do modelo de gestão composto pelos módulos já mencionados.

\section{ETAPA II: ESTADO GERENCIAL ATUAL DA EMPRESA PROJETISTA}

A Etapa de Pesquisa II tem por objetivo compreender o estado gerencial atual da empresa, a partir do levantamento das deficiências nas práticas de gestão que a empresa possui e das dificuldades encontradas durante a implementação do modelo de gestão e o desenvolvimento de ferramentas (ver Figura 1). O levantamento de dados da Etapa II foi realizado em julho de 2012, momento posterior à participação da empresa no PDGEP.

Nessa etapa, a técnica utilizada para a coleta de dados foi a entrevista estruturada. Foram realizadas entrevistas individuais com os dois sócios da empresa e o gerente administrativo-financeiro. As deficiências e as dificuldades relatadas por Souza (2009), relativas às edições de 2006 e 2007, foram utilizadas como referência para a elaboração do roteiro das entrevistas.

1 Mais detalhes referentes à rotina dos PDGEP's podem ser encontrados em Souza (2009) e Souza et al. (2011).

2 http://www.facebook.com/PDGEP 
Foram aplicadas 21 questões referentes às deficiências e 25 questões referentes às dificuldades.

A empresa estudada criou e desenvolveu um Sistema de Informações Gerenciais (SIG) durante a participação nas edições do PDGEP. Verificou-se, com a aplicação das entrevistas, quais módulos de gestão foram desenvolvidos e contemplados nessa ferramenta.

\section{FUNDAMENTAÇÃO TEÓRICA}

A primeira parte da fundamentação teórica deste artigo trata do modelo de gestão para empresas de projeto de edifícios proposto por Oliveira (2005). Na sequência, o referencial teórico trata dos itens contemplados no SIG criado pela empresa: gestão financeira, gestão de pessoas, gestão comercial e de marketing e gestão do processo de projeto.

\section{MODELO DE GESTÃO PARA EMPRESAS DE PROJETO DE EDIFÍcIOS}

De acordo com Oliveira (2005), os principais benefícios para as empresas de projeto e edifícios obtidos com a implementação do modelo de gestão referem-se ao aumento da confiabilidade e consequente redução de riscos - entregas de projeto no prazo, sem erros e sem incompatibilidades entre disciplinas; à melhoria da gestão de projetos contratados - melhor gestão de contratos, processos de contratação e controle facilitados, melhoria das relações entre empresas de projeto, contratantes e demais envolvidos no processo de projeto, melhor capacitação dos colaboradores internos e externos; e ao fortalecimento das práticas da gestão da empresa como um todo.

Conforme Oliveira e Melhado (2008), um dos maiores desafios para a melhoria de desempenho das empresas de projeto é a conscientização dos projetistas sobre as potencialidades que um sistema de gestão bem estruturado e voltado para qualidade pode proporcionar. Para que o modelo de gestão efetivamente gere os resultados esperados é necessário que as empresas de projeto e seus gestores:

- Tenham consciência de suas deficiências técnicas e de gestão;

- Estejam efetivamente dispostos a "mudar" e compreendam não só os potenciais benefícios que ele pode proporcionar, mas também os sacrifícios e desafios a serem suplantados;

- Efetivamente se preparem para implementá-lo;

- Desenvolvam os processos que compõem o modelo com intensidade seletiva, em função da realidade e necessidade de cada empresa.

O modelo de gestão (OLIVEIRA, 2005) trata das funções e processos administrativos essenciais às empresas de projeto, procurando privilegiar a simplicidade e flexibilidade dos procedimentos a serem desenvolvidos/ controlados.

Conforme mencionado anteriormente, o modelo é composto pelos seguintes módulos: estrutura organizacional, planejamento estratégico, planejamento e controle do processo de projeto, gestão financeira, gestão comercial e marketing, sistema de informação, gestão de pessoas e serviços agregados ao projeto e avaliação de desempenho (Figura 2).

Cada um dos módulos de gestão é descrito a seguir, por meio do detalhamento de seus objetivos no contexto da implementação do modelo em empresas de projeto.

No que se refere à estrutura organizacional, deve-se analisar como a estrutura da empresa permite a execução de suas estratégias e a realização 


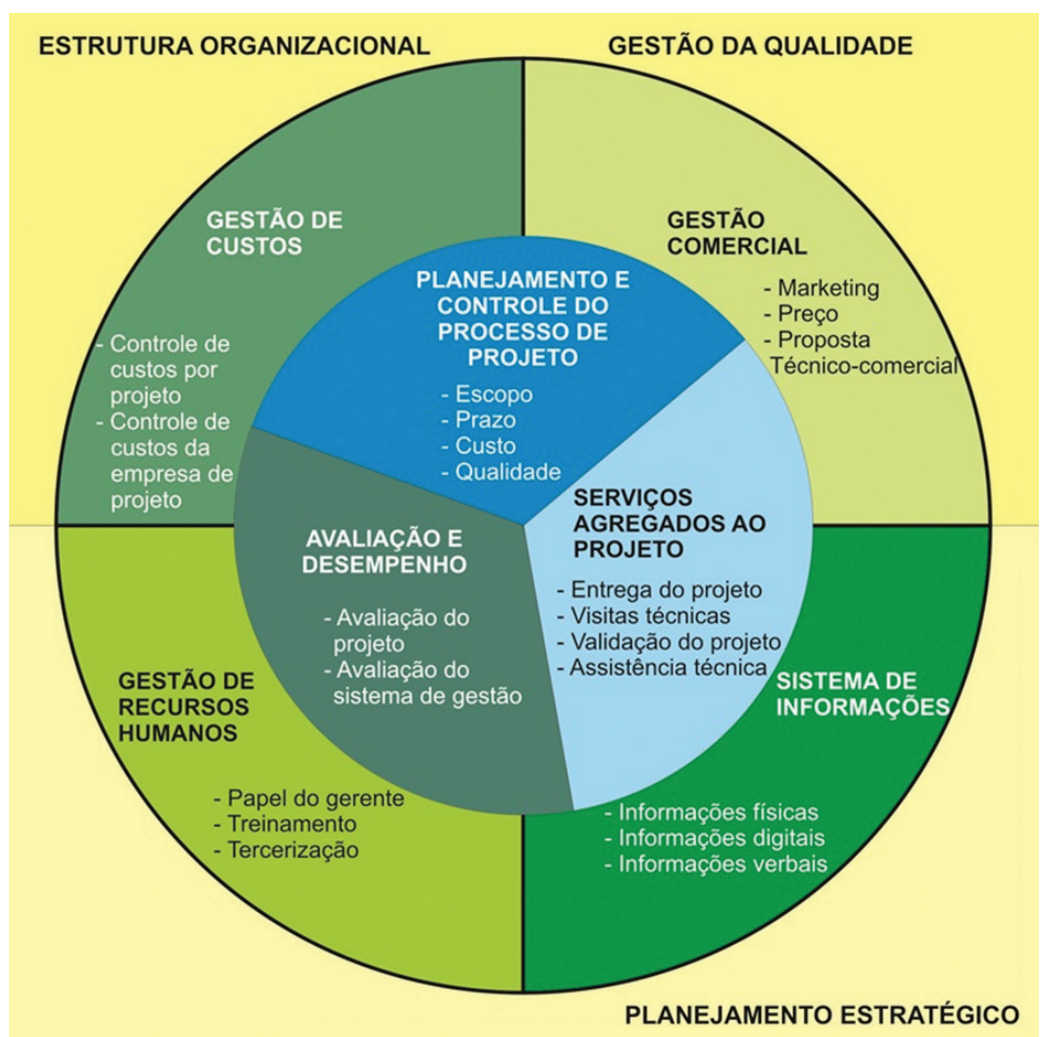

do seu trabalho. Além disso, deve-se considerar como a estrutura se harmoniza com os indivíduos que ali trabalham e qual é o impacto sobre as suas atividades.

O planejamento estratégico permite conhecer e melhor utilizar os pontos fortes da empresa; conhecer, eliminar ou adequar os seus pontos fracos; conhecer e aproveitar as oportunidades externas, assim como evitar as ameaças; criar uma agenda para objetivos e metas da empresa.

A elaboração de instrumentos para planejamento e controle do processo de projeto traz consideráveis benefícios ao processo de avaliação final do projeto, tanto em relação aos aspectos técnicos quanto com relação aos aspectos de gestão. Os dados advindos destes instrumentos possibilitam o estabelecimento de diretrizes para aprimoramento dos novos projetos, por meio da comparação entre as atividades previstas e as realmente realizadas.

No módulo de gestão financeira, instrumentos simplificados para organização e controle das receitas, dos custos fixos e dos custos diretos da pequena empresa de projetos de edifícios devem ser desenvolvidos.

Referente à gestão comercial e marketing, estratégias e ferramentas de marketing devem ser definidas com o objetivo de fazer com que o cliente perceba que o serviço "projeto" é parte indissociável do produto edifício, de modo a criar a sensação de necessidade desse serviço. Além disso, um método para precificação dos projetos deve ser estabelecido e as propostas técnico-comerciais devem ser elaboradas.

No âmbito de sistema de informação, mecanismos simples e consistentes para emissão, recebimento e armazenagem das informações necessárias para o processo de projeto e para a gestão da empresa de projeto devem ser criados, de modo a facilitar a disponibilidade e a quantidade da informação no momento certo.
Figura 2. Modelo de gestão para pequenas empresas de projeto. (Fonte: adaptada de Oliveira, 2005). 
Quanto à gestão de pessoas, procedimentos simples e básicos para a contratação de colaboradores, educação continuada e treinamento devem ser propostos, bem como para a organização das terceirizações, com enfoque para o aperfeiçoamento tecnológico dos profissionais, melhoria do clima organizacional e garantia de melhor qualidade dos projetos realizados pela empresa.

Quanto aos serviços agregados ao projeto, práticas devem ser estabelecidas com o objetivo de criar uma linha direta de comunicação com o cliente e usuários do projeto (contratante, obra e usuário da edificação), de modo a aperfeiçoar continuamente o processo de projeto.

No módulo de avaliação de desempenho, uma sistemática para avaliação do desempenho dos projetos desenvolvidos pela empresa e avaliação do desempenho do seu sistema de gestão deve ser proposta.

\section{REFERENCIAL TEÓRICO}

\section{Gestão financeira}

De acordo com Atkinson et al. (1989), a gestão financeira de uma empresa tem como objetivo melhorar continuamente o processo de planejamento e controle, de forma a fornecer informações que orientem a tomada de decisão, a fim de que os objetivos estratégicos, táticos e operacionais sejam atingidos. Para tanto, deve ser subsidiada por um sistema que agregue informações de todas as áreas da empresa: produção, comercial, pessoas, tecnologia e estratégica.

Segundo Pinto (2007), entende-se por gastos os sacrifícios financeiros com que a empresa arca para atingir seus objetivos (obtenção de um produto ou realização de um serviço). O gasto implica em desembolso, seja no presente ou no futuro. Os custos são efetuados para obtenção de bens ou serviços. Em empresas prestadoras de serviços, os custos compreendem todos os insumos utilizados na realização do serviço. As despesas compreendem os gastos realizados para geração da receita e administração da empresa, e os investimentos são os gastos realizados no presente que geram benefícios em períodos futuros.

O autor ressalta que outro aspecto relevante para a eficácia do sistema de informações contábil e financeiro refere-se à definição do sistema de acumulação de custos da empresa, que está diretamente relacionado ao seu sistema de produção, que pode ser classificado como: sistema de acumulação por ordem de produção ou encomenda, e sistema de acumulação por processo.

\section{Gestão de pessoas}

Segundo Fischer (2001), gestão de pessoas é a maneira pela qual as empresas se organizam para gerenciar e orientar o comportamento humano no trabalho. Para isso, estruturam-se definindo princípios, estratégias, políticas e práticas ou processos de gestão e, com uso desses mecanismos, implementam diretrizes e orientam o estilo de atuação dos gestores em sua relação com aqueles que nelas trabalham.

O modelo de gestão de pessoas adotado pelas empresas é influenciado tanto por fatores internos como por fatores externos, e para os diferentes contextos históricos e setoriais existem diferentes modalidades de gestão. Tudo que interfere de alguma maneira nas relações organizacionais pode ser considerado um componente do modelo de gestão de pessoas, e o comportamento organizacional não é produto direto de um processo de gestão, mas o resultado das relações pessoais, interpessoais e sociais que ocorrem na empresa. 
Para Chiavenato (1989), o processo básico da gestão de pessoas é constituído por quatro subprocessos interdependentes:

- Provisão: Quem trabalhará na organização?

- Aplicação: O que as pessoas farão na organização?

- Manutenção: Como manter as pessoas trabalhando na organização?

- Desenvolvimento: Como preparar e manter pessoas?

- Monitoração: Como saber quem são e o que fazem as pessoas?

\section{Gestão comercial e marketing}

A função do marketing dentro das empresas é, essencialmente, lidar com os clientes e com o mercado em geral. Segundo Kotler e Armstrong (2003), entender, criar, comunicar e proporcionar ao cliente valor e satisfação, constituem a essência do pensamento e da prática do marketing moderno. Nesse sentido, os autores definem marketing como o processo administrativo e social pelo qual indivíduos e grupos obtêm o que necessitam e desejam, por meio da criação, oferta e troca de produtos com os outros.

Ainda de acordo com Kotler e Armstrong (2003), as empresas bemsucedidas são aquelas que definem o mercado-alvo, identificam as necessidades e expectativas dos clientes, procuram satisfazer as necessidades desses mesmos clientes de forma rápida e eficaz, dedicam atenção à qualidade dos produtos e serviços, e estão decididamente orientadas para os clientes.

No contexto da pequena empresa, o planejamento de marketing não substitui o planejamento estratégico e deve ser elaborado em função das diretrizes e dos objetivos estratégicos estabelecidos pela sua alta direção. $\mathrm{O}$ acompanhamento das diretrizes de marketing da pequena empresa, junto com os acompanhamentos técnico, financeiro e de recursos humanos, devem ser utilizados como fonte de informação para a retroalimentação do planejamento estratégico (SOUZA, 2009).

\section{Gestão do processo de projeto}

Melhado (1994) define o projeto a partir de uma visão fundamentada pela qualidade como atividade de concepção de produto ou serviço, e pode ser entendido como um processo que utiliza um conjunto de dados de entrada e, ao final, deve garantir como dados de saída um grupo de soluções que respondem às necessidades dos clientes a quem o edifício se destina.

No Brasil, destaca-se como principal iniciativa setorial para o estabelecimento de um fluxo de trabalho estável e padronizado a ser seguido durante a elaboração dos projetos de um empreendimento, a criação dos diversos Manuais de Escopo de Projetos, trabalho esse conduzido pelas entidades que representam os profissionais de projeto (ABECE, ABRASIP, AsBEA, AGESC e ABRAVA, seguidas da ANP, ABAP e ABRIESP).

Segundo as entidades, o desenvolvimento desses manuais objetiva a implantação de uma política de melhoria contínua da qualidade na cadeia produtiva e de relações éticas entre os seus diversos intervenientes, pois a definição prévia do escopo dos serviços para a elaboração dos diversos projetos que compõem um empreendimento deve preceder o início da elaboração de qualquer um dos projetos.

O conceito proposto nos manuais de escopo parte da premissa da complexidade da atividade de projeto, que envolve, além da atividade projetual em si, diversas interfaces com outras especialidades técnicas, além da contínua e crescente exigência por parte da indústria da construção civil em se apresentarem projetos coerentes com os princípios de racionalização, planejamento e controle de obras. Os manuais produzidos podem e devem ser utilizados como referência para todos os que se relacionam com o processo 
de desenvolvimento imobiliário, possibilitando conhecimento pleno das diversas etapas do projeto contratado.

Além dos manuais de escopo, outros trabalhos focados tanto no exercício profissional do design manager, quanto no design management foram desenvolvidos, estão disponíveis e podem ser acessados facilmente por profissionais, com destaque para as seguintes publicações: Preparação da Execução de Obras (SOUZA; MELHADO, 2003); Gestão do Processo de Projeto de Edificações (SILVA; SOUZA, 2003); Coordenação de Projetos de Edificações (MELHADO, 2005).

\section{EVOLUÇÃO DA EMPRESA PROJETISTA DURANTE O PDGEP POR MEIO DO DESENVOLVIMENTO DE FERRAMENTAS DE GESTÃO}

\section{CARACTERIZAÇÃO DA EMPRESA ESTUDADA}

A empresa estudada é especializada em desenvolver projetos de esquadrias e fachadas em alumínio, atua há nove anos no mercado e seus principais clientes são incorporadoras e construtoras. Sua equipe é constituída por: dois sócios (arquiteta e engenheiro civil), um engenheiro civil, uma arquiteta, dois projetistas, dois estagiários, um administrador e um colaborador responsável pelo sistema de gestão da empresa e pela fiscalização de obras e de fornecedores.

\section{TRAJETÓRIA DA EMPRESA PROJETISTA}

Por meio da participação no PDGEP, os gestores da empresa projetista adquiriram familiaridade com o modelo de gestão proposto por Oliveira (2005). Enfatizou-se a importância de gerir “o escritório como uma empresa”, que possui diversos processos, muitas vezes com relação direta pouco perceptível, em contraposição à ênfase apenas na atividade principal do projetista, que é desenvolver projetos.

Conforme mencionado, a empresa estudada participou das edições

Figura 3. PDGEP A e B, ferramentas e módulos de gestão. do PDGEP em 2008, 2009 e 2010, porém o conteúdo do artigo se refere às participações iniciadas em 2008 e 2010, aqui denominados de "PDGEP A" e "PDGEP B" (ver Figura 3).

De acordo com a Figura 3, durante a realização do PDGEP A, a empresa trabalhou no desenvolvimento

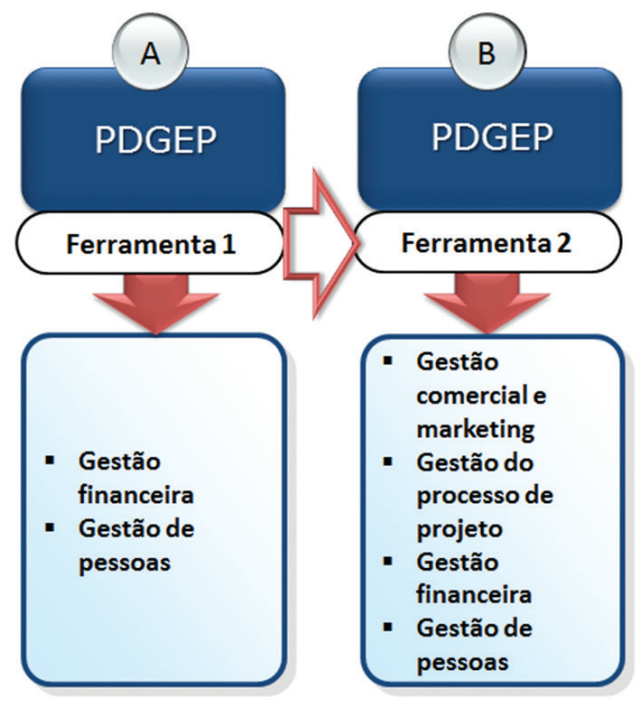
de uma ferramenta de gestão voltada para a gestão financeira e de pessoas (Ferramenta 1: Ferramenta para Análise da Gestão Financeira e Gestão de Pessoas). Durante aquela edição do programa, a empresa focou nesses módulos porque reconheceu a importância de possuir um método para apropriação correta de despesas e receitas e utilizá-la como instrumento de gestão (SOUZA et al., 2008).

Durante o PDGEP B, a empresa, por meio do desenvolvimento da Ferramenta de Gestão 1, elaborou a Ferramenta 2 (Controle de Horas, Versão 0) a partir das novas necessidades percebidas durante 0 trabalho realizado no módulo de gestão comercial e marketing. A Ferramenta 2 foi revisada a partir de outras necessidades advindas do módulo de gestão do processo de projeto, e constatadas após revisitar os processos de gestão financeira e gestão de pessoas. 
Considerando a experiência adquirida pela empresa no PDGEP A e a sua participação no PDGEP B, os próximos itens do artigo detalham o processo de criação e desenvolvimento da Ferramenta 2, tratada a seguir como SIG.

\section{ATUAÇÃO DA EMPRESA DURANTE O PDGEP B: DESENVOLVIMENTO DO SIG}

Conforme o item Etapa I: Programa de Desenvolvimento Gerencial para Empresas de Projeto, durante a participação no PDGEP B, a empresa estudada contou com a participação de um "colaborador de gestão", o qual foi fundamental para a criação e o desenvolvimento do SIG. O trabalho cotidiano desse colaborador teve como objetivo as atividades: organização das reuniões semanais na empresa para discussão dos processos e ferramentas de gestão; participação na elaboração dos diagnósticos de avaliação e das tarefas relacionados aos módulos; auxílio na formalização e implementação dos processos e das ferramentas de gestão; participação na análise das mudanças ocorridas nos processos da empresa, com base nos diagnósticos e nas tarefas realizados; acompanhamento da aplicação das ferramentas desenvolvidas; e elaboração de relatórios referentes ao andamento do trabalho.

Orientado pelos coordenadores do PDGEP, o "colaborador de gestão" definiu um roteiro para realização do trabalho em cada módulo de gestão, a partir das seguintes ações: realizar uma reunião inicial com os gestores da empresa para diagnosticar as deficiências e os pontos fortes da empresa relacionados ao módulo; verificar, no cotidiano da empresa, as respostas obtidas na reunião inicial; realizar uma reunião de retroalimentação e de propostas de melhoria; acompanhar a implementação das melhorias decididas na reunião anterior.

\section{Processo de criação e desenvolvimento do SIG}

Utilizando o roteiro descrito anteriormente como referência, foi analisada primeiramente a gestão comercial e marketing praticada na empresa. Os gestores observaram que não dispunham de ferramentas para determinação dos preços de seus produtos, condicionados fundamentalmente às horas despendidas por seus colaboradores na produção dos projetos. Este aspecto já havia sido observado pela empresa durante o PDGEP A. Na ocasião os gestores resolveram a questão com um procedimento bem simples: anotar em um caderno, para cada colaborador, todas as horas despendidas para desenvolver os projetos. Com o tempo, este sistema foi abandonado e a empresa passou a não controlar as horas gastas por projeto, consequentemente, a não dispor de dados para precificar adequadamente seus produtos.

Durante o PDGEP B, a empresa retomou a ideia de controlar as horas, e o colaborador de gestão se responsabilizou por criar e desenvolver uma ferramenta computadorizada para armazenar o número de horas de cada colaborador por projeto, por mês. A opção acordada foi a criação de uma planilha eletrônica com macros para automatizar os processos de inserção de horas e de contagem mensal - a ferramenta "Controle de Horas V0". A Figura 4 apresenta a evolução da ferramenta de gestão até a sua versão atual, destacando a inserção de controles (para mais detalhes, consultar Francischetti et al., 2011a). A “Controle de Horas V0" (Planilha 1 na Figura 4) computava somente as horas que cada colaborador despende em cada projeto.

A evolução da ferramenta de gestão ocorreu juntamente com as análises dos módulos de gestão. Na análise das práticas de gestão do processo de projeto, a empresa se deparou com a questão do planejamento da execução dos projetos. Até então, sem o controle das horas necessárias para a produção, a empresa tinha dificuldades em determinar com exatidão a 


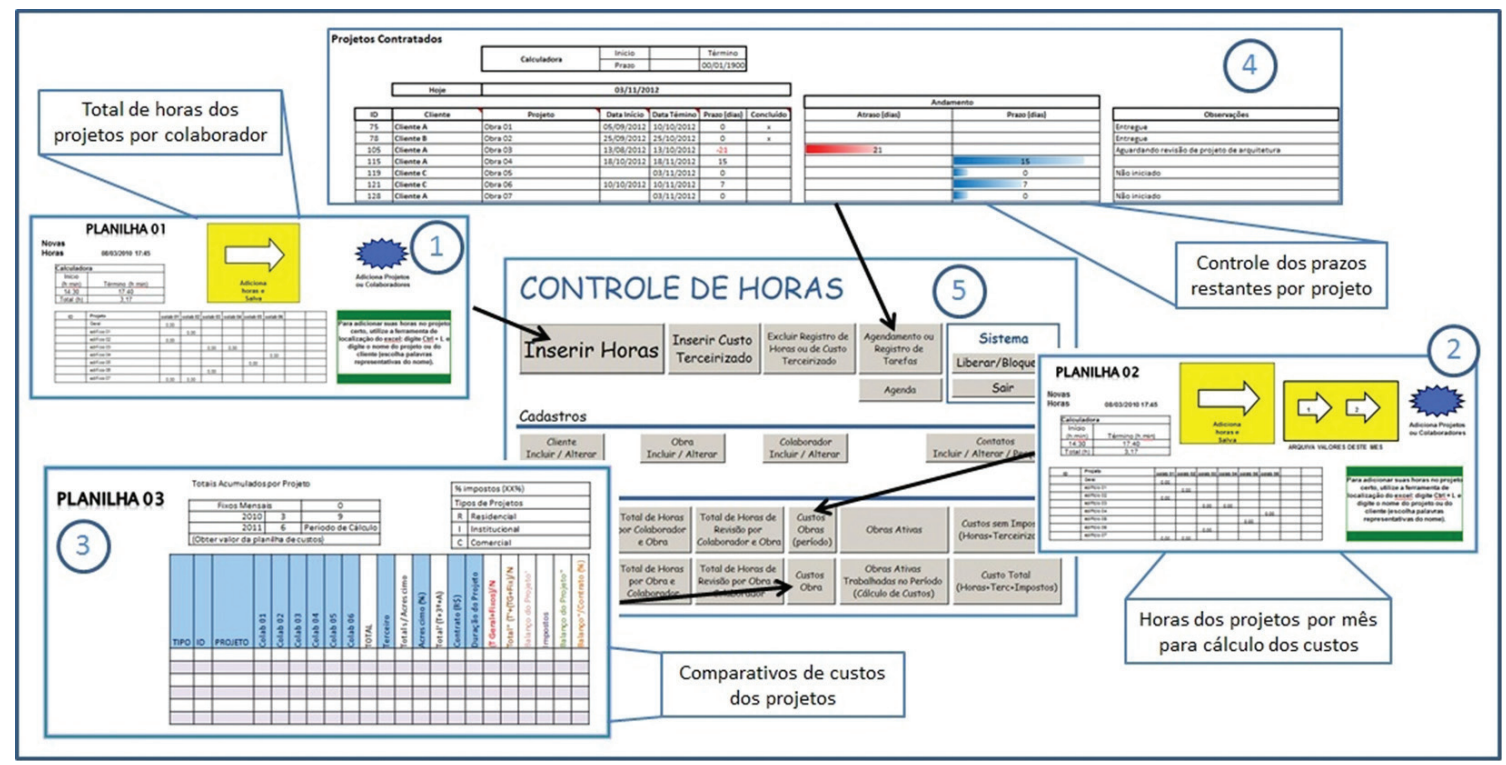

Figura 4. Evolução da ferramenta de gestão "Controle de Horas". viabilidade econômica, a demanda por recursos (horas dos colaboradores, principalmente) e a duração de cada projeto. A partir daí, a empresa confirmou a necessidade da sua ferramenta "Controle de Horas", que estava em uso há aproximadamente um mês e meio, e passou a identificar melhor as interfaces existentes entre os processos, buscando extrair diversos dados da ferramenta, relacionados com os módulos de gestão (gestão comercial e marketing, gestão do processo de projeto etc.).

No que se refere à gestão de pessoas, a empresa observou que o controle das horas despendidas para cada projeto poderia gerar indicadores de produtividade, não só para avaliar o volume mensal produzido por cada colaborador, mas também para identificar os tipos de projetos que demandam mais recursos (recursos humanos: horas dos colaboradores), permitindo optar por produzir certos tipos de produtos ou contratar novos colaboradores.

Analisando a gestão financeira da empresa, os gestores observaram que, apesar de haver melhor controle dos recursos humanos (produtividade, disponibilidade e capacidade produtiva), ainda não dispunham dos custos destes recursos - parcela do custo total dos projetos referente às horas despendidas pelos colaboradores. Para resolver esta questão, outras macros foram acrescentadas à ferramenta para realizar os cálculos dos custos parciais mensais de cada projeto, uma vez que se tinham os valores das horas técnicas de cada colaborador em cada mês (Planilha 2 na Figura 4). Com isso, surgiram as planilhas de controles financeiros da ferramenta "Controle de Horas", que estava em uso há cerca de seis meses.

Posteriormente, os gestores da empresa sugeriram uma nova planilha que realizasse, de forma automática, um comparativo entre projetos (Planilha 3 da Figura 4), separando-os em categorias e permitindo analisar as melhores opções de produtos a serem oferecidos pela empresa, retomando a ideia discutida durante a análise da gestão comercial e marketing, que dependia dos valores que esta planilha agora apresentava.

Nesta nova planilha foram inseridos dados de outras planilhas de controle financeiro, como os custos fixos da empresa e os valores dos contratos de cada projeto. Além disso, a ferramenta permitiu realizar uma comparação entre os vários projetos em função do tempo demandado, dos custos totais, e do tipo de cada um (se era um projeto para edifício comercial, edifício 
residencial, hospital, centro de educação etc.). Com as alterações, a planilha passou a armazenar um grande volume de dados e, com isso, algumas macros levavam um tempo maior para serem executadas. Além disso, os dados não podiam ser inseridos simultaneamente na ferramenta.

Com a contratação de um novo colaborador, os gestores receberam sugestões de melhoria da ferramenta. Este colaborador, com conhecimento de um software específico, sugeriu a transferência da planilha eletrônica para um banco de dados, dispondo-se a contribuir no processo de melhoria. Assim, iniciou-se o desenvolvimento de uma ferramenta mais complexa, completa, e com recursos adicionais de gestão de atividades e prazos (Planilha 4 da Figura 4): a "Controle de Horas V2" (Banco de Dados 5 da Figura 4). O Banco de Dados resolveu os problemas de lentidão e acesso simultâneo.

A ferramenta "Controle de Horas V2", agora denominada SIG, é atualizada sempre que se identifica alguma nova necessidade de informações ou possibilidade de uso pelos colaboradores ou gestores de maneira bem simples, com a inserção de novas tabelas, formulários e/ou relatórios, sem interferir no uso da ferramenta ou nos dados já armazenados.

\section{O SIG em 2012}

Atualmente o SIG da empresa possui nove cadastros e 29 relatórios. O Quadro 1 apresenta estes cadastros e os relatórios gerados a partir de suas informações.

Conforme mencionado no item Atuação da empresa durante o PDGEP B: Desenvolvimento do SIG, o SIG contempla os módulos de gestão comercial e marketing, gestão do processo de projeto, gestão financeira e gestão de pessoas. O Quadro 2 relaciona os módulos de gestão e os relatórios contidos no sistema.

Considerando o Quadro 2, as potencialidades de evolução gerencial da empresa estudada são discutidas no item Discussão: potencialidades de evolução gerencial da empresa projetista.

\section{ESTADO GERENCIAL ATUAL DA EMPRESA}

\section{DEFICIÊNCIAS GERENCIAIS APRESENTADAS PELA EMPRESA}

Conforme já mencionado, as questões aplicadas durante o levantamento das deficiências visaram compreender quais módulos do modelo de Oliveira (2005) já haviam sido desenvolvidos pela empresa e como foram incorporados ao SIG. As questões relativas às deficiências foram elaboradas com base na pesquisa realizada por Souza (2009). Na ocasião, a autora diagnosticou as principais deficiências apresentadas pelas empresas participantes durante as edições do PDGEP de 2006 e 2007.

As questões para o levantamento das deficiências foram organizadas em seis blocos: planejamento estratégico e estrutura organizacional; gestão do processo de projeto; gestão financeira; gestão de pessoas; gestão comercial; serviços agregados e desempenho. Uma vez que as questões propostas foram fechadas, as possibilidades de resposta se limitaram a quatro opções: o item foi trabalhado, está sendo trabalhado, a trabalhar e não é possível avaliar. Para cada uma das respostas foram anotadas as observações relevantes colocadas pelos profissionais entrevistados.

Como parte do diagnóstico, foi avaliado se cada um dos módulos de gestão do modelo de Oliveira (2005) foi incorporado ou não ao SIG por meio das seguintes questões:

- O item foi diretamente contemplado no sistema?

- O sistema gera informações sobre o item? 
Quadro 1. Cadastros e relatórios do SIG.

\begin{tabular}{|c|c|c|c|c|c|c|c|c|c|}
\hline $\begin{array}{l}\text { CADASTROS } \rightarrow \\
\text { RELATÓRIOS } \downarrow\end{array}$ & 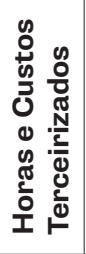 & $\begin{array}{l}\stackrel{g}{d} \\
\stackrel{\underline{c}}{0} \\
\frac{.0}{U}\end{array}$ & 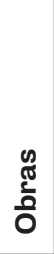 & $\begin{array}{l}\frac{1}{0} \\
\frac{0}{0} \\
\frac{1}{8} \\
\frac{0}{0} \\
\frac{0}{\pi} \\
\frac{\pi}{0} \\
0\end{array}$ & 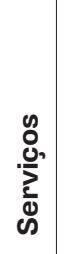 & 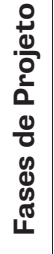 & 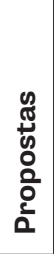 & 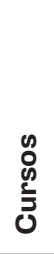 & 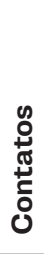 \\
\hline Lista de Contatos & & & & & & & & & $x$ \\
\hline Andamento das Propostas & & & & & & & $x$ & & \\
\hline Propostas Não Fechadas (Período) & & & & & & & $x$ & & \\
\hline Lista de Propostas de um Cliente & & & & & & & $x$ & & \\
\hline Todas as Obras & & & $x$ & & & & & & \\
\hline Obras Cadastradas (Período) & & & $x$ & & & & & & \\
\hline Obras Ativas & & & $x$ & & & & & & \\
\hline Obras Encerradas (Período) & & & $x$ & & & & & & \\
\hline Horas ou Custos (Lista geral) & $x$ & & $x$ & & & & & & \\
\hline Horas ou Custos (individualmente) & $x$ & & $x$ & & & & & & \\
\hline Andamento do Projeto & & & $x$ & & & & & & \\
\hline Agenda & & & $x$ & & & & & & \\
\hline Acompanhamento dos Prazos dos Projetos & & & $x$ & & & & & & \\
\hline Cronograma & & & $x$ & & & & & & \\
\hline Inclusões efetuadas (dia) sem Terceirizados & $x$ & & & & & & & & \\
\hline Inclusões efetuadas (dia) com Terceirizados & $\mathrm{x}$ & & & & & & & & \\
\hline Horas por Colaborador (Período) & $\mathrm{x}$ & & & & & & & & \\
\hline Horas por Fase (Período) & $\mathrm{x}$ & & $\mathrm{x}$ & & $x$ & $x$ & & & \\
\hline Verif. incluído Cliente X Horas/Custo & $x$ & & $x$ & & & & & & \\
\hline Total de Horas por Colaborador (Obra) & $x$ & & & & & & & & \\
\hline Total de Horas por Obra (Colaborador) & $\mathrm{x}$ & & & & & & & & \\
\hline Total de Horas de Revisão por Colaborador (Obra) & $x$ & & & & & & & & \\
\hline Total de Horas de Revisão por Obra (Colaborador) & $x$ & & & & & & & & \\
\hline Custos Obra Específica & $\mathrm{x}$ & & $x$ & & & & & & \\
\hline Custos Obras (período) & $x$ & & & & & & & & \\
\hline Obras Ativas Trabalhadas Período (Cál. de Custos) & $\mathrm{x}$ & & $x$ & & & & & & \\
\hline Custo Total (Horas + Terceirizados + Impostos) & $\mathrm{x}$ & & $\mathrm{x}$ & & & & & & \\
\hline Custos sem Impostos (Horas + Terceirizados) & $\mathrm{x}$ & & & & & & & & \\
\hline Cursos & & & & $x$ & & & & $x$ & \\
\hline
\end{tabular}

De forma geral, ocorreu convergência entre as respostas dadas pelos três entrevistados. No entanto, um aspecto interessante percebido durante as entrevistas se referiu ao processo de projeto. Quando questionados se a empresa desenvolveu processos e ferramentas para a gestão desse processo, os três entrevistados responderam que foram desenvolvidos os processos e ferramentas. No entanto, não houve convergência das respostas quando questionados sobre a sistemática de análise crítica sobre a eficácia dos instrumentos de gestão. Dessa forma, verifica-se que a gestão do processo de 
Quadro 2. Relação dos módulos de gestão com os relatórios gerados pelo SIG

\begin{tabular}{|l|l|}
\hline \multicolumn{1}{|c|}{ Módulos de Gestão } & \multicolumn{1}{c|}{ Relatórios do SIG } \\
\hline Gestão comercial e marketing & $\begin{array}{l}\text { Lista de Contatos, Andamento das Propostas } \\
\text { Propostas Não Fechadas (Período), Lista de Propostas de um Cliente }\end{array}$ \\
Gestão do processo de projeto & $\begin{array}{l}\text { Todas as Obras, Obras Cadastradas (Período), Obras Ativas (sem } \\
\text { registro de data de encerramento), Obras Encerradas (Período), }\end{array}$ \\
& Andamento do Projeto, Agenda, Acompanhamento dos Prazos dos \\
& Projetos, Cronograma, Inclusões efetuadas (dia) sem Terceirizados, \\
& Inclusões efetuadas (dia) com Terceirizados \\
Gestão do processo de projeto, & Horas ou Custos (Lista geral), Horas ou Custos (individualmente), Horas \\
gestão financeira & por Fase (Período), Verificação se foi incluído corretamente Cliente X \\
& Horas/Custo, Total de Horas por Obra (Colaborador), Total de Horas de \\
& Revisão por Obra (Colaborador), Custos Obra Específica, Custos Obras \\
Gestão do processo de projeto, & (período) \\
gestão financeira, gestão de pessoas & Horas por Colaborador (Período), Total de Horas por Colaborador \\
Gestão financeira & (Obra), Total de Horas de Revisão por Colaborador (Obra) \\
& Obras Ativas Trabalhadas no Período (Cálculo de Custos), \\
Gestão de Pessoas & Custo Total (Horas + Terc + Impostos), Custos sem Impostos \\
& (Horas + Terceirizados) \\
\hline & Cursos \\
\hline
\end{tabular}

projeto ainda é deficiente na empresa, uma vez que ainda predomina a falta de sistematização na análise crítica dos instrumentos de gestão desenvolvidos.

Quanto ao planejamento estratégico, os produtos oferecidos pela empresa estão definidos e, apesar de o escopo referente ao trabalho de projeto executivo estar formalizado, o escopo dos trabalhos referentes ao projeto preliminar ainda está por formalizar.

Destaca-se como ponto de atenção e aspecto ainda a melhorar, a falta de formalização do planejamento estratégico. Embora a empresa tenha adotado a prática de reunir-se ao final de todos os anos para fazer um balanço do ano que passou e definir ações para o próximo período, foi relatado pelos entrevistados que as decisões tomadas nessas reuniões não são desdobradas em objetivos, metas e ações mensuráveis. Outro aspecto preocupante refere-se à utilização das informações geradas a partir do SIG, as quais não são devidamente analisadas no processo de tomada de decisões estratégicas da empresa.

A evolução quanto à gestão financeira e a gestão comercial é evidenciada em virtude dos relatórios gerados pelo SIG, conforme destacados no Quadro 2. No que se refere à gestão financeira, o sistema possibilita a geração de relatórios gerenciais a partir da organização das despesas diretas e indiretas, bem como dos custos fixos e variáveis. Quanto à gestão comercial, as informações geradas possibilitam as análises e tomada de decisão a partir do controle de resultados por projeto, cliente e produto.

No que se refere à gestão de pessoas, a empresa desenvolveu procedimentos e ferramentas voltados ao processo seletivo, no entanto, ainda não desenvolveu uma sistemática para avaliação dos profissionais. Embora a empresa pratique divisão de lucros com os colaboradores, os critérios para essa divisão não são pautados em critérios claros e pré-acordados de avaliação. Outro ponto de atenção em relação à gestão de pessoas está relacionado à subutilização do sistema nesse aspecto. Apesar do cadastro de realização de cursos e treinamentos estar previsto no módulo de gestão de 
pessoas do SIG, o seu planejamento não é praticado, ocorrendo a partir do surgimento de oportunidades, demandas imediatas e pontuais.

Como a empresa não pratica terceirizações, não existe a necessidade do seu planejamento, de acordo com o modelo de Oliveira (2005).

Outra deficiência da empresa refere-se ao módulo de serviços agregados. Apesar de a empresa ter desenvolvido uma base de indicadores para avaliação do processo de projeto e da empresa por meio do SIG, tais indicadores são coletados internamente. A empresa estruturou um processo e criou ferramentas para a realização da avaliação da satisfação dos clientes externos, mas só fez a aplicação uma vez - sobre a aplicação, consultar Francischetti et al. (2011b). Segundo a empresa, não foi dada continuidade ao processo em virtude das dificuldades inerentes à realização de uma pesquisa de satisfação bem feita e também porque entende que "se os clientes a contratam novamente, é porque o nível de satisfação é adequado”, o que pode ser questionável.

\section{DIFICULDADES APRESENTADAS PELA EMPRESA NO DESENVOLVIMENTO GERENCIAL}

Assim como no levantamento das deficiências, o levantamento das dificuldades foi realizado com base na pesquisa realizada por Souza (2009). Na ocasião, a autora diagnosticou as principais dificuldades apresentadas pelas empresas participantes das edições de 2006 e 2007 do PDGEP para a implementação do modelo de gestão proposto por Oliveira (2005).

As respostas mostradas no quadro na primeira linha referem-se às respostas do Gerente Administrativo Financeiro (a), na segunda linha estão as respostas da Sócia responsável pelos processos comerciais (b) e na terceira linha, as respostas do Sócio responsável pelos processos técnicos (c).

As questões para o levantamento do nível de dificuldade da empresa foram organizadas em seis blocos: planejamento estratégico e estrutura organizacional; gestão do processo de projeto; gestão financeira; gestão de

Quadro 3. Dificuldades apresentadas pela empresa no desenvolvimento gerencial.

\begin{tabular}{|c|c|c|c|c|c|c|}
\hline Dificuldades: Planejamento Estratégico e Estrutura Organizacional & $\mathbf{E}$ & 1 & 2 & 3 & 4 & 5 \\
\hline \multirow[t]{3}{*}{ Prática de planejamento estratégico, contemplando as análises interna e externa } & a & & & & & \\
\hline & $b$ & & & & & \\
\hline & $c$ & & & & & \\
\hline \multirow[t]{3}{*}{ Definição de objetivos, metas e indicadores } & a & & & & & \\
\hline & $b$ & & & & & \\
\hline & c & & & & & \\
\hline \multirow[t]{3}{*}{ Definição de suas atividades e seus produtos } & a & & & & & \\
\hline & $b$ & & & & & \\
\hline & c & & & & & \\
\hline \multirow[t]{3}{*}{ Definição das funções, atribuições e responsabilidades } & a & & & & & \\
\hline & $b$ & & & & & \\
\hline & c & & & & & \\
\hline \multirow[t]{3}{*}{ Definição da estrutura organizacional } & a & & & & & \\
\hline & $b$ & & & & & \\
\hline & c & & & & & \\
\hline
\end{tabular}


Quadro 3. Continuação...

\begin{tabular}{|c|c|c|c|c|c|c|}
\hline Dificuldades: Gestão do Processo de Projeto & $\mathbf{E}$ & 1 & 2 & 3 & 4 & 5 \\
\hline \multirow[t]{3}{*}{ Desenvolvimento de ferramentas para gestão do processo de projeto } & a & & & & & \\
\hline & $b$ & & & & & \\
\hline & c & & & & & \\
\hline \multirow[t]{3}{*}{ Utilização das ferramentas de gestão do processo de projeto } & a & & & & & \\
\hline & b & & & & & \\
\hline & c & & & & & \\
\hline \multirow[t]{3}{*}{ Tomada de decisões baseada nas informações da gestão do processo de projeto } & a & & & & & \\
\hline & $b$ & & & & & \\
\hline & c & & & & & \\
\hline
\end{tabular}

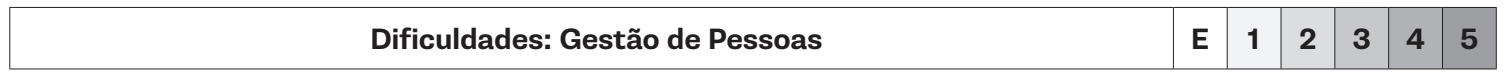

Desenvolvimento do processo de gestão de pessoas

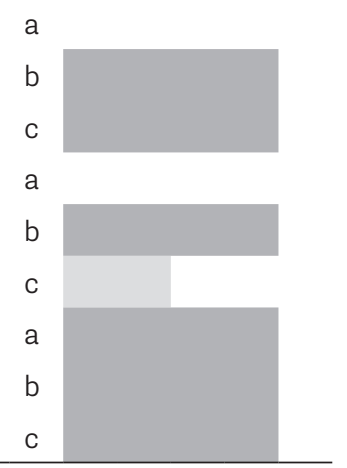

\begin{tabular}{|c|c|c|c|c|c|c|}
\hline Dificuldades: Gestão Financeira & $\mathbf{E}$ & 1 & 2 & 3 & 4 & 5 \\
\hline \multirow[t]{3}{*}{ Caracterização do fluxo de informações para a gestão financeira } & a & & & & & \\
\hline & $\mathrm{b}$ & & & & & \\
\hline & C & & & & & \\
\hline \multirow[t]{3}{*}{ Desenvolvimento do processo de gestão financeira e ferramentas } & a & & & & & \\
\hline & $\mathrm{b}$ & & & & & \\
\hline & C & & & & & \\
\hline \multirow[t]{3}{*}{ Aplicação do processo de gestão financeira } & a & & & & & \\
\hline & b & & & & & \\
\hline & C & & & & & \\
\hline \multirow[t]{3}{*}{ Tomada de decisões baseada nas informações do sistema de gestão financeira } & a & & & & & \\
\hline & $\mathrm{b}$ & & & & & \\
\hline & $\mathrm{C}$ & & & & & \\
\hline
\end{tabular}


Quadro 3. Continuação...

\begin{tabular}{|c|c|c|c|c|c|c|}
\hline Dificuldades: Gestão Comercial & $\mathbf{E}$ & 1 & 2 & 3 & 4 & 5 \\
\hline \multirow[t]{3}{*}{ Revisão do processo de gestão comercial (incluindo proposta técnico-comercial) } & a & & & & & \\
\hline & b & & & & & \\
\hline & C & & & & & \\
\hline \multirow[t]{3}{*}{ Desenvolvimento do processo de gestão comercial } & a & & & & & \\
\hline & $b$ & & & & & \\
\hline & c & & & & & \\
\hline \multirow[t]{3}{*}{ Aplicação do processo de gestão comercial } & a & & & & & \\
\hline & b & & & & & \\
\hline & c & & & & & \\
\hline \multirow[t]{3}{*}{ Tomada de decisões baseada no processo de gestão comercial } & a & & & & & \\
\hline & $\mathrm{b}$ & & & & & \\
\hline & c & & & & & \\
\hline
\end{tabular}

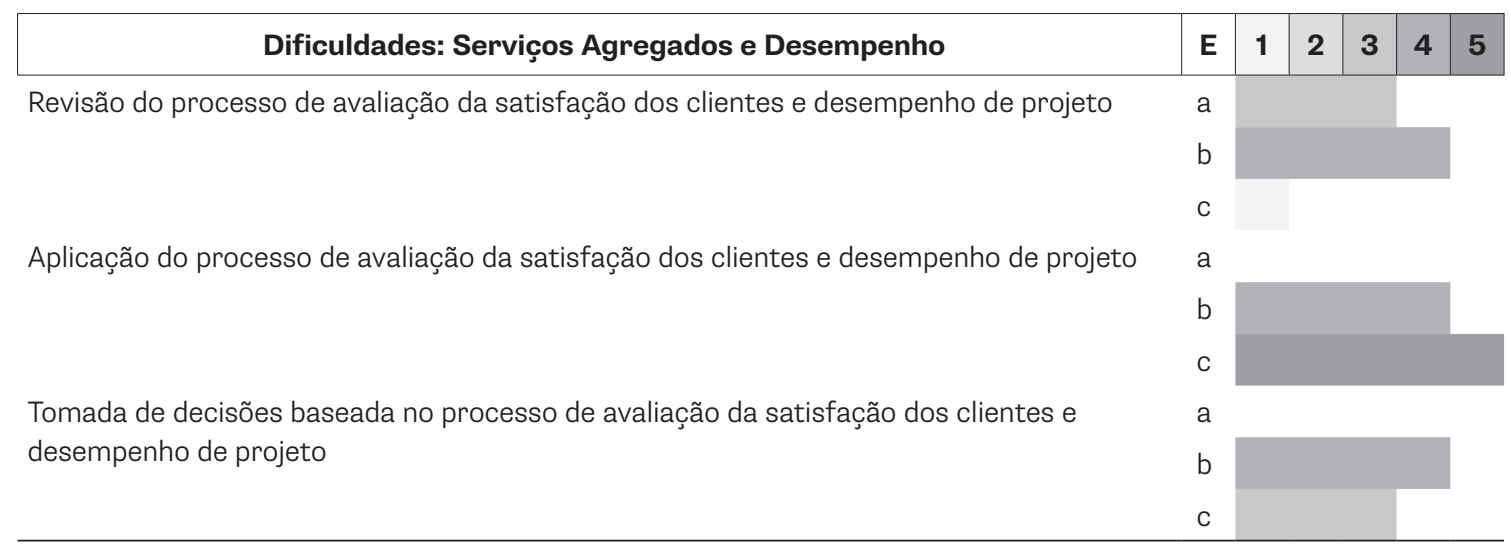

\begin{tabular}{|c|c|c|c|c|c|c|}
\hline Dificuldades: Sistema de Informação & $\mathbf{E}$ & 1 & 2 & 3 & 4 & 5 \\
\hline \multirow{3}{*}{$\begin{array}{l}\text { Desenvolvimento do sistema de informação, contemplando: processo de projeto, RH, } \\
\text { gestão financeira, gestão comercial }\end{array}$} & a & & & & & \\
\hline & $b$ & & & & & \\
\hline & c & & & & & \\
\hline \multirow{3}{*}{$\begin{array}{l}\text { Aplicação do sistema de informação, contemplando: processo de projeto, RH, gestão } \\
\text { financeira, gestão comercial }\end{array}$} & a & & & & & \\
\hline & b & & & & & \\
\hline & C & & & & & \\
\hline \multirow{3}{*}{$\begin{array}{l}\text { Tomada de decisão baseada no sistema de informação, contemplando: processo de } \\
\text { projeto, RH, gestão financeira, gestão comercial }\end{array}$} & a & & & & & \\
\hline & $b$ & & & & & \\
\hline & C & & & & & \\
\hline
\end{tabular}

pessoas; gestão comercial; serviços agregados e desempenho. Os entrevistados avaliaram o nível de dificuldade numa escala crescente, variando de 1 a 5.

Em geral, analisando o Quadro 3, verifica-se que os entrevistados avaliaram a maior parte dos itens com nível de dificuldade acima de 3 . Outro aspecto interessante refere-se à dificuldade na tomada de decisão, já 
que a maior parte das respostas aponta para um alto nível de dificuldade em relação a esse ponto.

Em geral, os dados sobre o nível de dificuldade da empresa na implementação do modelo de gestão de Oliveira (2005) demonstram o quão estão consolidados na empresa os conceitos implícitos no mesmo.

Dessa forma, as respostas sobre os módulos de gestão do processo de projeto, comercial e marketing e financeira retratam a postura da empresa durante a participação no PDGEP A e B, uma vez que ao longo desse período foi dado por parte da empresa maior ênfase em relação a esses módulos.

A partir do comportamento descrito, verifica-se que os aspectos conceituais sobre os referidos módulos estão consolidados na empresa, justificando as respostas contidas no Quadro 3.

Em relação aos módulos planejamento estratégico e estrutura organizacional, gestão de pessoas e serviços agregados, o Quadro 3 mostra um alto nível de dificuldade.

Confrontando os dados coletados sobre deficiências, discutidos no item Deficiências gerenciais apresentadas pela empresa, verifica-se que os processos e ferramentas para contratação de pessoas não são utilizados com frequência em função da baixa rotatividade na empresa. Embora, sob o ponto de vista de gestão estratégica, a baixa rotatividade de colaboradores seja um fato positivo para a empresa, sob o ponto de vista da gestão de pessoas, acaba gerando uma acomodação negativa por parte da direção em relação a esse processo, uma vez que, segundo Chiavenato (1989), o processo básico além da provisão e aplicação, contempla manutenção, desenvolvimento e monitoração.

Com base no exposto, a não consolidação do processo de gestão de pessoas é apresentado no Quadro 3 por meio do nível de dificuldade no nível 4.0 mesmo ocorre com planejamento estratégico e estrutura organizacional e serviços agregados.

Quanto às dificuldades apontadas sobre sistemas de informações, verificou-se que, apesar do desenvolvimento do SIG ter sido uma grande evolução para a empresa sob o ponto de vista gerencial, a forma como foi desenvolvido denota que o conceito de gestão da informação necessita ser reavaliado para que o SIG possa ser considerado uma ferramenta gerencial efetiva. $\mathrm{O}$ conceito torna-se mais complexo à medida que permeia todos os módulos de gestão contemplados por Oliveira (2005).

\section{DISCUSSÃO: POTENCIALIDADES DE EVOLUÇÃO GERENCIAL DA EMPRESA PROJETISTA}

A partir da Etapa de Pesquisa I (ver Figura 1), é possível identificar os principais avanços que ocorreram na empresa, por meio da implementação do modelo de gestão e desenvolvimento de ferramentas.

De forma geral, os gestores têm evoluído no sentido de compreender e, na medida do possível, aplicar os conceitos de gestão envolvidos em cada módulo (OLIVEIRA, 2005; ATKINSON et al. 1989; FISCHER, 2001; CHIAVENATO, 1989; KOTLER; MELHADO, 1994). A participação da empresa em mais de uma edição do programa "Soluções” reforçou essa compreensão.

A construção do SIG possibilitou aos gestores a observação de interfaces entre elementos aparentemente dissociados, por meio do desenvolvimento da visão sistêmica sobre a gestão da empresa, impactando positivamente no seu core business que é desenvolver projetos.

Nesse sentido, destaca-se como demanda para o SIG a necessidade do cruzamento de dados decorrentes da gestão de pessoas com gestão financeira, 
com objetivo de gerar informações para análises estratégicas voltadas à expansão da empresa.

Souza (2009) observou que os primeiros planos e ferramentas, desenvolvidos pelas empresas de projeto envolvidas em sua pesquisa, normalmente eram incoerentes com as suas características e limitações; portanto, de difícil aplicação. Conforme a autora, nos trabalhos de desenvolvimento gerencial, as revisões são recorrentes, qualquer que seja o método de trabalho escolhido, pois os equívocos iniciais, a percepção de outras necessidades, e posteriores revisões fazem parte do processo. Deste modo, a predisposição para a constante "ação-reflexão-ação" é fundamental para o amadurecimento empresarial.

O processo de criação e desenvolvimento da ferramenta de gestão apresentado corrobora as afirmações de Souza (2009), já que a ferramenta foi modificada conforme as reflexões dos gestores e colaboradores sobre os dados e as informações necessárias, passando a considerar os diferentes módulos de gestão envolvidos e suas interfaces.

A partir da Etapa de Pesquisa II (ver Figura 1), observa-se que a empresa ainda apresenta deficiências gerenciais, principalmente no que se refere aos seguintes aspectos:

- Desenvolvimento de uma sistemática de análise crítica sobre a eficácia dos instrumentos de gestão, relacionados ao processo de projeto da empresa;

- Necessidade da formalização do planejamento estratégico e sistematização das análises. É importante destacar que a empresa realiza uma reunião anual, composta por um balanço do ano e perspectivas para o próximo, porém não desdobra os assuntos em objetivos, estratégias, metas e indicadores;

- Revisão do processo de gestão de pessoas. Atenção especial deve ser dada ao desenvolvimento de uma sistemática para avaliação dos colaboradores, com estabelecimento de critérios claros e pré-acordados para a divisão de lucros praticada na empresa. O SIG pode ser utilizado como suporte ao processo de gestão de pessoas como um todo, hoje o processo se resume ao registro de horas trabalhadas e de cursos no sistema (ver Quadro 2);

- Revisão do módulo de serviços agregados, especialmente no que se refere à revisão e aplicação da avaliação da satisfação dos clientes;

- Realização de análises críticas sistemáticas do SIG, principalmente no que se refere à criação de relatórios. Atualmente o sistema apresenta inúmeros relatórios, alguns dos quais gerando informações redundantes.

\section{CONSIDERAÇÕES FINAIS}

A empresa projetista percorreu um longo caminho, conforme descrito no item Evolução da empresa projetista durante o PDGEP por meio do desenvolvimento de ferramentas de gestão. Ao longo desse processo, apresentou dificuldades na implementação do modelo de gestão, porém criou e desenvolveu o seu SIG, sem o apoio de um software de gestão pronto, buscando conhecer as suas necessidades. Tal percurso possibilitou o seu amadurecimento organizacional, garantindo que a empresa esteja pronta para evoluir ainda mais.

Em seu estado gerencial atual, é importante que a empresa realize a revisão dos módulos de gestão e uma análise crítica sistemática do SIG, verificando a possibilidade de evolução gerencial a partir das recomendações deste artigo. Nesse sentido, recomenda-se que a análise crítica do sistema seja pautada na otimização das informações por ele geradas. 
A partir de uma análise criteriosa do SIG no item O SIG em 2012, verificou-se um número elevado de relatórios, muitos dos quais gerando informações redundantes. Esse é um ponto de atenção tanto do ponto de vista de infraestrutura de sistemas quanto de eficácia da sua utilização.

O sistema deve fornecer informações estruturadas a partir de seus relatórios, em função das demandas gerenciais da empresa; por isso, a definição de um relatório é uma das etapas mais relevantes do processo de criação de um sistema gerencial.

Nesse sentido, é fundamental que a definição desses relatórios seja otimizada, ou seja, antes da criação de um relatório, as demandas gerenciais devem ser levantadas, analisadas e estruturadas. A partir desse processo, os dados necessários para geração da informação devem ser identificados, para então, serem cruzados pelo sistema, gerando assim a informação a ser analisada para posterior tomada de decisão.

Em linhas gerais, os relatórios de um sistema gerencial devem ser definidos com objetivo de suprir as demandas gerenciais de uma empresa sob os pontos de vista estratégico, tático e operacional.

De forma geral, existe por parte dos gestores das empresas de projeto dificuldade em entender as inter-relações entre os diversos processos de gestão das suas empresas. Portanto, torna-se fundamental que o desenvolvimento gerencial de tais empresas seja estruturado a partir da visão sistêmica num processo de constante autocrítica, não limitado pela implementação de um modelo de gestão, pois é pouco provável que uma empresa seja adequadamente organizada a partir de avaliações superficiais sobre sua conduta, limitações e possibilidades.

Nesse sentido, a consolidação do Programa de Desenvolvimento Gerencial para Empresas de Projeto (PDGEP), conforme relatado nesse artigo, deu-se em virtude da abertura de um espaço no qual as empresas projetistas podem discutir as suas questões gerenciais e desenvolver soluções específicas para suas demandas. Os modelos de gestão e diversos trabalhos de pesquisa desenvolvidos no âmbito do programa não são utilizados como solução padrão para as questões levantadas pelas empresas. Ao contrário, os modelos e experiências acumuladas no grupo são os meios utilizados para a condução das discussões com as empresas.

Nesse sentido, mais relevante do que o desenvolvimento de ferramentas e procedimentos, é a transformação da postura do gestor em relação à sua empresa e ao contexto no qual ela está inserida. Tal transformação passa pela ciência da importância da constante autocrítica; logo, a inserção estratégica no segmento no qual a empresa está inserida, é a consequência natural desse processo.

\section{AGRADECIMENTOS}

Os autores agradecem à empresa ARQMATE Consultoria e Projetos de Esquadrias, em especial à arquiteta Maria Teresa Faria e Godoy, pela contribuição ao estudo; ao Leandro Francischetti pela colaboração; e à CAPES e ao CNPq pelas bolsas de pesquisa concedidas às autoras. 


\section{REFERÊNCIAS}

ATKINSON, A. A. et al. Advanced management accounting. 2nd ed. Englewood Cliffs: Prentice Hall, 1989.

CHIAVENATO, I. Administração de Recursos Humanos. São Paulo: Atlas, 1989.

\section{FISCHER, A. Gestão por}

Competências. 4. ed. São Paulo: Gente, 2001.

FRANCISCHETTI, L. et al. Criação e desenvolvimento de uma ferramenta de gestão em empresa de projeto. In: SIMPÓSIO BRASILEIRO DE QUALIDADE DO PROJETO NO AMBIENTE CONSTRUIIDO, 2., WORKSHOP BRASILEIRO DE GESTÃO DO PROCESSO DE PROJETO NA CONSTRUÇÃO DE EDIFÍCIOS, 10., 2011, Rio de Janeiro. Anais... Rio de Janeiro: PROARQ/FAU/ UFRJ, PPG-IAUSC USP, 2011 .

FRANCISCHETTI, L. et al. Aplicação de avaliação da satisfação do cliente contratante pela empresa de projeto. In: SIMPÓSIO BRASILEIRO DE QUALIDADE DO PROJETO NO AMBIENTE CONSTRUÍDO, 2., WORKSHOP BRASILEIRO DE GESTÃO DO PROCESSO DE PROJETO NA CONSTRUÇÃO DE EDIFÍCIOS, 10., 2011, Rio de Janeiro. Anais... Rio de Janeiro: PROARQ/FAU/ UFRJ, PPG-IAUSC USP, 2011b.

KOTLER, P.; ARMSTRONG, G. Princípios de Marketing. Tradução de Arlete Simille Marques, Sabrina Cairo; revisão técnica de Dilson Gabriel dos Santos, Francisco J. S. M. Alvarez. 9. ed. São Paulo: Prentice Hall, 2003. PMCid:PMC2173688.

MELHADO, S. B. Qualidade do projeto na construção de edifícios: aplicação ao caso das empresas de incorporação e construção. 1994. 294 f. Tese (Doutorado em Engenharia de Construção Civil e Urbana)-Escola Politécnica, Universidade de São Paulo, São Paulo, 1994.

MELHADO, S. B. (Coord.). Coordenação de projetos de edificações. São Paulo: O Nome da Rosa, 2005. PMCid:PMC1490266.
OLIVEIRA, O. J. Modelo de gestão para pequenas empresas de projeto de edifícios. 2005. 262 f. Tese (Doutorado em Engenharia de Construção Civil e Urbana)-Escola Politécnica, Universidade de São Paulo, São Paulo, 2005.

OLIVEIRA, O. J.; MELHADO, S. B. Proposta de um modelo de gestão para pequenas empresas de projeto de edifícios. Gestão \& Tecnologia de Projetos, v. 3, n. 2, nov. 2008.

PINTO, E. P. Gestão Empresarial. Casos e Conceitos da Evolução Organizacional. São Paulo: Saraiva, 2007.

SILVA, M. A. C.; SOUZA, R. Gestão do Processo de Projeto de Edificações. São Paulo: O Nome da Rosa, 2003.

SOUZA, A. L. R.; MELHADO, S. B.

Preparação da execução de obras. São Paulo: O Nome da Rosa, 2003.

SOUZA, F. R. Implementação de modelo de gestão para empresas de projeto. 2009. 202 f. Dissertação (Mestrado em Engenharia de Construção Civil)-Escola Politécnica, Universidade de São Paulo, São Paulo, 2009.

SOUZA, F. et al. Implementação do modelo de gestão para pequenas empresas de projeto. Análise da etapa de gestão financeira e gestão de recursos humanos em uma empresa de projeto de esquadrias. In: WORKSHOP BRASILEIRO DE GESTÃO DO PROCESSO DE PROJETOS NA CONSTRUÇÃO DE EDIFÍCIOS, 8., 2008, São Paulo. Anais... São Paulo: USP, 2008.

SOUZA, F. R. et al. O Programa de Desenvolvimento Gerencial para Empresas de Projeto. In: CONFERÊNCIA INTERNACIONAL DA LARES, 11., 2011, São Paulo. Anais... São Paulo: LARES, 2011.

THIOLLENT, M. Metodologia da pesquisa-ação. 14. ed. São Paulo: Cortez, 2005.

\footnotetext{
Correspondência

Flávia Souza, flavia.rodrigues.souza@gmail.com Nathália de Paula, nathaliapaula@yahoo.com.br

Silvio Burrattino Melhado, silvio.melhado@poli.usp.br
} 